\title{
Machado de Assis: a literatura fantástica no conto $O$ Imortal
}

\section{Vítor Castelões Gama* Werbson Azevedo Laurentino ${ }^{* *}$}

\author{
"O conto, enquanto vida, acaba também \\ encantando [...] contando estórias, vai adiando a \\ morte e prolongando a vida" \\ Nádia Battela Gotlib, Teoria do conto.
}

\begin{abstract}
Resumo: A narrativa fantástica contém a ruptura entre o real e o irreal promovendo a quebra da estabilidade fixa ao apresentar o conflito do impossível como um mistério a ser desvendado, se é que é possível. Com isso em mente, a narrativa machadiana nos apresenta um universo em que a presença do real e do contraditório são marcantes, gerando dúvidas nas personagens bem como nos leitores. No presente artigo, analisaremos o conto O Imortal tendo em vista as definições do fantástico de Todorov.
\end{abstract}

Palavras-Chave: Literatura Fantástica. Machado de Assis. O Imortal.

Abstract: The fantastic contains the rupture between the real and the unreal, promoting the
breaking of fixed stability by presenting the conflict of the impossible as a mystery to be
unraveled, if such a thing is possible. With this in mind, the Machado narrative presents us with
a universe in which the presence of the real and the contradictory are striking, generating doubts
in the characters as well as in the readers. In the present paper we will analyze the short story
The Immortal with the aid of Todorov's definition of the fantastic. Keywords: Fantastic. Machado de Assis. The Immortal.

Resumen: La narrativa fantástica contiene la ruptura entre lo real y lo irreal, promoviendo la ruptura de la estabilidad fija al presentar el conflicto de lo imposible como un misterio que debe ser develado, si es posible. Con esto en mente, la narración de Machado nos presenta un universo en el que llama la atención la presencia de lo real y lo contradictorio, generando dudas tanto en los personajes como en los lectores. En este artículo analizaremos el relato El Inmortal a la luz de las definiciones de lo fantástico de Todorov.

\footnotetext{
* Doutorando em Literatura e Práticas Sociais na Universidade de Brasília. http://orcid.org/oooo-oooz2343-3047

${ }_{* *}^{*}$ Mestre em Literatura e Práticas Sociais na Universidade de Brasília. http://orcid.org/oooo-0002-7201$\underline{2436}$
} 
Palabras-clave: Fantástico. Machado de Assis. El Inmortal.

Os pesquisadores Bruno Matangrano e Enéias Tavares (2018, p. 43) ressaltam que elementos presentes em Machado de Assis delinearam muito do que viria a se tornar norma no fantástico brasileiro do século XX. Também apontam os autores que apesar da importância do gênero e para o gênero, o fantástico em Machado é visto como um assunto "secundário". Diante disso, buscamos compreender como são utilizados os elementos fantásticos nas narrativas de Machado, mais especificamente no conto "O Imortal”. Vale observar também o lapso temporal subjacente na proposta dos pesquisadores citados: por que a influência fora sentida mais fortemente no século XX e não no XVIII e XIX? Um fator importante, a ser posto na balança no que diz respeito aos contos fantásticos do século XVIII e XIX é que o Racionalismo, enquanto corrente filosófica prevalecente no período, defendia o uso da razão como o elemento paradigmático que explicaria todos os fatos, inclusive o sobrenatural. É desse período também o surgimento da Religião da Humanidade que expressa que a religião científica revelaria o mundo de modo mais preciso que o mundo da fantasia. As convenções estéticas e literárias dessa época se expressavam no Realismo. "Sabe-se que o romance realista europeu, tributário do otimismo racionalista do século XIX, pressupunha a história como um processo que vai em direção a um fim ótimo" (FIGUEIREDO, 2010, p. 91). ${ }^{1}$ Para combater a presença maciça do fator científico, o elemento de mistério passa a figurar de modo mais presente nas narrativas. Uma estratégia que se encontraria balanceada em Edgar Allan Poe.

Ao estudar a obra fantástica machadiana, a pesquisadora Lucélia Silva (2018, p. 9495) encontrou várias referências do autor às obras de Poe, especialmente nos contos, como, por exemplo, em "A Segunda Vida” de Machado, onde refere-se à “Metzengerstein” do escritor americano. Destaca-se também que Machado foi um dos tradutores das obras do escritor citado. A influência é, portanto, demonstrável. Para o teórico David Roas (2014, p. 169)

\footnotetext{
${ }^{1}$ Auguste Comte, com sua "Religião da Humanidade" é uma das principais referências dessa corrente racionalista do séc. XIX.
} 
os autores surgidos na esteira de Poe desenvolveram uma visão do fantástico em que esse cientificismo (e a importante dimensão psicológica) das obras do autor norte-americano se unia às exigências de "verificação" do positivismo e às reivindicações da escola realista-naturalista.

Consequentemente, a intenção dos autores seria apresentar o mistério como componente que inquietaria o sujeito, estimulando sua curiosidade e, portanto, desestabilizaria o discurso científico com suas leis rigorosas e imutáveis a respeito do mundo. Logo, estariam contrapostos o discurso da crença - que traria a quebra da estabilidade ao apresentar o impossível -, com o discurso científico do mundo sólido e seguro garantido pela razão.

A conceituação do fantástico começou a ser delineada no início do século XX. Tzvetan Todorov é um dos grandes proponentes da corrente do fantástico como gênero, junto do estranho e do maravilhoso. A diferenciação entre eles se daria em consequência da posição adotada frente a um acontecimento narrativo. Se esse acontecimento fosse explicado utilizando-se parâmetros naturais e científicos, a obra seria explicada pelo gênero estranho. De outra forma, se o acontecimento fosse elucidado admitindo-se a existência de novas leis da natureza, ter-se-ia o gênero maravilhoso. Já o gênero fantástico deveria atender três condições básicas, dentre essas, duas seriam necessárias e uma apenas desejada.

\begin{abstract}
Este exige que três condições sejam preenchidas. Primeiro, é preciso que o texto obrigue o leitor a considerar o mundo dos personagens como um mundo de criaturas vivas e a hesitar entre uma explicação natural e uma explicação sobrenatural dos acontecimentos evocados. A seguir, esta hesitação pode ser igualmente sentida por um personagem; desta forma, o papel de leitor é, por assim dizer, confiado a uma personagem e ao mesmo tempo a hesitação se encontra representada, torna-se um dos temas da obra; no caso de uma leitura ingênua, o leitor real se identifica com a personagem. Enfim, é importante que o leitor adote uma certa atitude para com o texto: ele recusará tanto a interpretação alegórica quanto a interpretação 'poética'. Estas três exigências não têm valor igual. A primeira e a terceira constituem verdadeiramente o gênero; a segunda pode não ser satisfeita. Entretanto, a maior parte dos exemplos preenchem as três condições (TODOROV, 2017, p. 38-39).
\end{abstract}

"Qualquer explicação que possa ser realizada no estranho ou no maravilhoso poderia pôr fim ao fantástico" (SÁ, 2003, p. 32). Eis a razão porque para Todorov o conceito de fantástico é de ordem eminentemente restritiva, visto que ele exclui o maravilhoso 
como também o estranho da narrativa fantástica. Entretanto, esta visão não é unanimidade entre os estudiosos do gênero. Para o teórico espanhol David Roas (2014, p. 89), a conceituação de Todorov é lacunar em diversos aspectos, por exemplo, poucas narrativas manteriam a hesitação do começo ao fim. Na proposta de Roas, a hesitação sai do pedestal e cede lugar para a apreciação da realidade e seus limites. O mais importante agora é o conflito entre o possível e o impossível. Sendo assim, um exame da realidade externa se faz necessário por parte do leitor, que deve decidir pela inexplicabilidade do fenômeno ou não. Cabe ressaltar, então, que

apesar das diferenças existentes entre quase todas as abordagens [...] verifica-se que elas concordam por completo num ponto, pelo menos: qualquer narrativa fantástica encena invariavelmente fenômenos ou seres inexplicáveis e, na aparência, sobrenaturais (FURTADO, 1980, p. 19).

A diegese possui um clima de histórias contadas ao redor da fogueira. Três interlocutores estão unidos para ouvir a história de um homem que, apesar de imortal, morreu. Logo de início percebe-se a quebra de um princípio lógico das leis naturais, algo bem característico ao estilo machadiano. $\mathrm{O}$ narrador do conto, conhecido apenas como Dr. Leão, um médico homeopata, relata a vida de Ruy de Leão, seu pai, para os atentos personagens Coronel Bertioga e o tabelião João Linhares.

Sabe-se que Ruy de Leão tomou o hábito no convento de Iguaraçu onde ficou até o lugar ser invadido por holandeses. Após certo tempo da ocupação neerlandesa foi-lhe oferecido uma escolha pelos invasores, ficar ou sair. O espírito aventureiro de Ruy de Leão o compeliu a buscar novos ares e sua busca pareceu findada ao encontrar uma tribo indígena. Nesta tribo viveu contente e se casou pela primeira vez. Também é nessa aldeia que o elemento insólito será apresentado. Seu sogro, quando próximo da morte mostrou um segredo: um remédio feito por um xamã que imortalizaria quem o bebesse. A primeira reação foi sugerir que o sogro tomasse o elixir, mas a dúvida logo lhe abateu, pois acreditava que o índio estava delirante devido a uma enfermidade terminal:

Meu pai não acreditou na virtude do elixir. Era absurdo supor que um tal líquido pudesse abrir uma exceção na lei da morte. Era naturalmente algum remédio, se não fosse algum veneno; e neste caso, a mentira do índio estava explicada pela turbação mental que meu pai lhe atribuiu (ASSIS, 2006, p. 889). 
Ruy esqueceu-se do remédio até o momento que ficou doente e, nesse momento, após beber metade do conteúdo, recuperou a saúde. Cabe ressaltar que, a imortalidade, neste caso, não veio de poderes divinos ou acontecimentos mágicos, mas de um ato corporal: a ingestão de um líquido. Ademais, de forma extremamente racionalizada pelo narrador: "A ciência de um século não sabia de tudo; outro século vem e passa adiante. Quem sabe, dizia ele consigo, se os homens não descobrirão um dia a imortalidade, e se o elixir científico não será esta mesma droga selvática?" (ASSIS, 2006, p. 890). De modo que o elixir é apresentado e aceito, pelos ouvintes, como uma ciência desconhecida. Sustenta a justificativa dada pelo narrador a estrutura do discurso no conto, cada ato que ocorre na narrativa possui uma consequência e segue um procedimento básico: "a exposição linear, a complicação e a explicação" (HANSEN, 2006, p. 62-63). É quase como um método científico, condizente ao estilo da época marcado pela influência de Edgar Allan Poe.

Entretanto, ao mesmo tempo em que Machado produz esse argumento lógico para o elixir, esta visão racional é contestada pela possibilidade sobrenatural e vice-e-versa. $\mathrm{O}$ fato de o elixir ser apresentado por um indígena é essencial para que o leitor da época possa apreciar o conto. O índio por "conhecer" os rituais antigos e secretos pode "reviver" os tempos míticos. Ou, em outras palavras, supostamente possuiria uma conexão com as forças da natureza não entendida pela racionalidade científica. É importante que haja certa indeterminação nos fatos, pois como ressalta David Roas (2014, p. 166), esta é uma das formas de se tornar o conto fantástico mais palatável para o leitor inexperiente, uma vez que ao distanciar os fatos no tempo e espaço a narrativa tornava-se mais verossímil. Por isto, o elixir foi preparado por um pajé de longe, muito longe.

Nesse sentido, logo no início do conto, quando um dos ouvintes corrige a data do nascimento do pai do Dr. Leão, tenta mudar o registro da narração, transformando o fantástico que começa a ser contado em gênero realista baseado em opiniões tidas por "naturais". Mas o Dr. Leão insiste e mantém a história como gênero fantástico. Assim, quando diz que ela não é fácil de crer, joga com a dupla perspectiva da recepção, que já apareceu na correção feita por um dos ouvintes: a história não é fácil de crer, se for lida por meio da verossimilhança positivista-realista; mas é totalmente crível se for lida como gênero fantástico, que aplica convenções críveis para narrar o incrível (HANSEN, 2006, p. 72-73). 
A dificuldade inicial é suspender a descrença, mas que pouco a pouco os personagens vão cedendo. Mesmo perplexos, os personagens participam do diálogo contando os casos bíblicos de Matusalém e Lamech, "mas explicou logo, porque era um espírito forte, que esse e outros exemplos da cronologia hebraica não tinham fundamento científico..." (ASSIS, 2006, p. 891).

Retomando à diegese, a imortalidade começou a fazer seus efeitos em Ruy, que imediatamente angustiou-se. "Moço, perpetuamente moço. A vida do mato começara a aborrecê-lo; ficara ali por gratidão ao sogro; as saudades da civilização vieram tomá-lo” (ASSIS, 2006, p. 890). Assim que a mulher morreu, Ruy resolveu adentrar ao mundo. Mais uma vez seu espírito aventureiro falou mais alto:

Que o amor, força é dizê-lo, foi uma das causas da vida agitada e turbulenta do nosso herói. Ele era pessoalmente um homem galhardo, insinuante, dotado de um olhar cheio de força e magia. Segundo ele mesmo contou ao filho, deixou muito longe o algarismo don-juanesco das mille e tre (ASSIS, 2006, p. 891-892).

A razão de sua felicidade também era de tristeza. A angústia natural que perpassa a imortalidade, a solidão; pois sendo o único de sua espécie não é possível compartilhar sua vida com um companheiro, talvez por isso cogitasse dividir a dádiva com "alguma senhora ou homem", mas não o fez. Da mesma forma, não era possível viver como imortal. Uma vez que assim o fizesse, no momento que fincasse raízes, seria descoberto e, possivelmente, aprisionado. Esse fato expressa mais um dos efeitos trazidos pela imortalidade, a incompreensão dos que são mortais. À vista disso, tinha que viver da maneira mais corriqueira possível.

O que acontece ao personagem de "O imortal" é ser e fazer muito, acumulando e vivendo demasiadamente na sua os vários possíveis das vidas de outros homens: pernambucano, religioso franciscano, amante de índia, amante de lady escocesa, guarda papal, rei de Inglaterra, traficante de escravos, soldado, espião etc. A história incomum de sua vida é efetivamente uma história esticada como somatória, por assim dizer, de existências, escolhas e ações de muitos homens. Nos diversos momentos dos seus 255 anos, variam enormemente as pessoas e as experiências; no entanto, em todas as situações que vive, ano após ano, entre 1639 e 1855, sempre se lê a mesma história básica. Como se, vivendo o impossível da imortalidade, a cada nova experiência estivesse condenado a efetivamente viver as possibilidades restritas de uma vida só mortal, repetindo na longa extensão da sua as mesmas poucas experiências da vida breve de todos, o amor, a aventura e a intriga (HANSEN, 2006, p. 6o). 
É tamanha a quantidade de aventuras de Ruy que o narrador comenta:

Já vêem, pelo que lhes contei, que não acabaria hoje nem em toda esta semana, se quisesse referir miudamente a vida inteira de meu pai. Algum dia o farei, mas por escrito, e cuido que a obra dará cinco volumes, sem contar os documentos... (ASSIS, 2006, p. 893).

Porém, a vida de eterna repetição era um suplício e o vazio que sentia não era preenchido por nada e logo tentou o suicídio:

"Filho", dizia-me ele, contando-me o episódio; “dei seis golpes, cada um dos quais bastava para matar um homem, e não morri." Desesperado, saiu de casa, e atirouse ao mar. $\mathrm{O}$ mar restituiu-o à terra. A morte não podia aceitá-lo: ele pertencia à vida por todos os séculos" (ASSIS, 2006, p. 896).

Não havia perspectiva de mudança e isso lhe levou ao estado agravado de melancolia. "A alma de meu pai chegara a um grau de profunda melancolia. Nada o contentava; nem o sabor da glória, nem o sabor do perigo, nem o do amor. [...] Vegetava consigo; triste, impaciente, enjoado" (ASSIS, 2006, p. 899). Segue-se a mais uma constatação infeliz, o que era "bênção" transformou-se em condenação. A vida eterna era um dos piores castigos, vivia em um tédio absurdo e refletindo sobre a própria vida, aconselhou ao filho que não desejasse tal maldição.

Tinha provado tudo, esgotado tudo; agora era a repetição, a monotonia, sem esperança, sem nada. Tinha de relatar a outros filhos, vinte ou trinta séculos mais tarde, o que me estava agora dizendo; e depois a outros, e outros, e outros, um não acabar mais nunca (ASSIS, 2006, p. 900).

Entretanto, no início do conto afirma-se que o imortal havia morrido, como isto é possível? A história conta que Ruy, seguindo um princípio homeopático, teria resolvido o problema: "Similia similibus curantur. Bebera o resto do elixir, e assim como a primeira metade lhe dera a vida, a segunda dava-lhe a morte. E, dito isto, expirou" (ASSIS, 2006, p. 900). Há uma insinuação presente na história de que talvez esta teria sido inventada para vender produtos homeopáticos, isso se torna mais notório pelas falas iniciais: "Andava propagando o novo sistema” e “- Não tenho interesse em contar-lhes a vida de meu pai, 
respondeu o Dr. Leão” e mais “- Querem ouvir-me?”. Mas, se o narrador não ia contar a história do pai, qual história que seria contada? Indica-se que os ouvintes é que identificam a história como a do pai do Dr. Leão, que por esse motivo entra no jogo e expõe a história fantástica aos incrédulos interlocutores.

Outra fala presente no conto afirma que "chegando aos cinquenta, cinquenta e poucos, voltava para trás; - e era-lhe fácil fazer isto, porque não esquentava lugar; vivia cinco, oito, dez, doze anos numa cidade, e passava a outra.... (ASSIS, 2006, p. 893). Dessa forma, a história se torna mais intrigante, pois o Dr. Leão era também recém-chegado à cidade. Poderia ser ele mesmo o imortal. Por outro lado, a própria asseveração do narrador deixa a possibilidade de que a narrativa foi feita apenas para vender remédio. Devemos lembrar que José Dias, de Dom Casmurro, se apresenta como homeopata. Mas a homeopatia naquele contexto histórico ainda tinha status científico. Neste sentido, Machado criticaria a ciência homeopática ou seus praticantes, ou é apenas um recurso para o fantástico?

Mas a suspeita de que ele apenas quis propagar a homeopatia entrou em alguns cérebros, e não era inverossímil. Dou este problema aos estudiosos. Tal é o caso extraordinário, que há anos, com outro nome, e por outras palavras, contei a este bom povo, que provavelmente já os esqueceu a ambos (ASSIS, 2006, p. 900).

Essa repetição da história ganha um ar de complexidade, pois parece haver mais uma vez uma subversão dos padrões lógicos. Seria o narrador aquele que teria vivenciado o que foi contado? Se esse for o caso, a diegese ganha mais um mistério, uma vez que o personagem teria de alguma forma conseguido vencer todas as angústias que a imortalidade traz e seguiria com a vida normal. A possibilidade de o narrador ser também o personagem imortal é corroborada também pelos aspectos metatextuais da narrativa, prefigurando a tendência do conto fantástico contemporâneo em fazer referência aos próprios métodos. Por exemplo, há o diálogo com o leitor "nos termos em que o leitor vai ver, se dar ao trabalho de ler o segundo e outros capítulos” (ASSIS, 2006, p.89o). Que servem pra instabilizar ainda mais as fronteiras entre o real e o irreal. ${ }^{2}$

\footnotetext{
${ }^{2}$ Ressaltamos que esta é uma característica frequentemente usada em contos fantásticos contemporâneos, mas não é necessariamente um indicativo da presença do fantástico na obra Machadiana. Isto por que o diálogo do narrador com o leitor, por exemplo, é uma tópica da tradição narrativa, desde o séc.XIX, em
} 
Essa retórica do indizível também possui uma evidente dimensão autorreflexiva, pois são constantes as representações críticas da enunciação e da própria atividade narrativa [...], assim como os jogos com a metaficção, recurso muito frequente na narrativa contemporânea em geral. Como diz Mellier, a metaficção designa algumas estratégias textuais que põem em crise a ilusão de realidade postulada pela mimese (ROAS, 2014, p. 172-173).

Como o narrador afirma já ter contado tal história com outro nome e agora a repete, contando com a falta de memória do povo é outro aspecto do jogo metatextual, uma que remete a um conto similar publicado por Machado de Assis, dez anos antes, chamado "Rui de Leão". Ou seja, um conto com outro nome e já “esquecido”.

Quando se aproxima ao fim da narrativa percebe-se que até mesmo o mais experimentado nas “técnicas" da razão parecia estar "caindo” no conto.

E teimou com o Dr. Leão para contar tudo, acrescentando que nunca ouvira nada tão extraordinário. Note-se que o tabelião presumia ser lido em histórias antigas, e passava na vila por um dos homens mais ilustrados do Império; não obstante, estava pasmado (ASSIS, 2006, p. 900).

Ao final da história tem-se a constatação: "O coronel e o tabelião ficaram algum tempo calados, sem saber que pensassem da famosa história; mas a seriedade do médico era tão profunda, que não havia duvidar. Creram no caso, e creram também definitivamente na homeopatia" (ASSIS, 2006, p. 900).

Ao retomar a discussão inicial, é forçoso constatar que "O Imortal” parece não pertencer ao seu período histórico, ao menos em relação à estrutura utilizada, que remete ao conto fantástico contemporâneo. Igualmente, a leitura todoroviana não elucida satisfatoriamente o conto analisado, pois, não é possível decidir se a dúvida, como conceito, persiste. Ou, se o acontecimento é explicado de forma racional ou "maravilhosa". A crítica especializada em geral, costuma ressaltar que a definição proposta por Todorov é mais adequado aos contos fantásticos do século XIX, mas, neste caso analisado começam a falhar, pois,

outros autores (como Alencar e Macedo) e independente do gênero fantástico. Da mesma forma a metaficção pode ser traçada de autores com Laurence Sterne, entre outros. 
Machado, e nisso ele se faz acompanhar de outros grandes escritores da tradição ocidental, nunca se deixou capturar completamente pelas tendências de um momento, produzindo, ao contrário, uma obra que atravessou diversas escolas ou movimentos, assimilando e ao mesmo tempo criticando aspectos de cada uma delas (COUTINHO, 2010, p. 84).

Roxana Álvarez (2011, p. 249) comenta que a presença do elemento sobrenatural em algumas narrativas de Machado deve ser vista como recurso retórico, utilizado para convencer personagens e/ou leitor de um argumento favorável ao narrador/escritor. E ante o exposto, "tal texto seria passível de ser considerado fantástico ou o aparente desvirtuamento no uso do fato sobrenatural bastaria para procurar outro gênero para classificá-lo?” (ÁLVAREZ, 2011, p. 249). Para a pesquisadora, alguns dos contos de Machado não poderiam ser vistos como pertencentes ao gênero fantástico, pois os elementos sobrenaturais eram subvertidos para outras reflexões. Entrementes, discordamos da inexistência do fantástico, mesmo que não perfeitamente fiel ao gênero como entendido em sua época. O elemento fantástico, um incidente insólito no qual toda a história gravita, é a ironia machadiana. Pois ao deixar o leitor em suspensão completa, a narrativa parece sugerir que cabe ao leitor o papel julgador da história. Logo, na construção do conto há a subversão das etapas todorovianas, essa se afigura como a estratégia de Machado - uma hesitação que não se resolve. Por esse motivo este conto não pode ser encaixado completamente nas circunscrições de Todorov. Afinal, possui todos os gêneros ao mesmo tempo, o maravilhoso, o fantástico e o estranho. E são essas indefinições que seriam aproveitadas por muitos escritores que viriam depois de Machado.

\section{Referências}

ÁLVAREZ, Roxana. G. Herrera. "Sem olhos", de Machado de Assis: conto fantástico? In: VOLOBUEF, Karin.; ÁLVAREZ, Roxana. G. Herrera.; WIMMER, Norma. Dimensões do fantástico, mítico e maravilhoso. São Paulo: Cultura Acadêmica, 2011. p. 241-265.

ASSIS, Machado de. Obra completa. Vol. II. Rio de Janeiro: Nova Aguilar, 2006 
COUTINHO, Eduardo. F. Machado e Rosa: um olhar além de seu tempo. In: FANTINI, Marli. Machado e Rosa: leituras críticas. São Paulo: Ateliê Editorial, 2010. p. 83-90.

FIGUEIREDO, Vera Lúcia F. de. O legado de Machado de Assis. In: FANTINI, Marli. Machado e Rosa: leituras críticas. São Paulo: Ateliê Editorial, 2010. Cap. 7, p. 91-102.

FURTADO, Filipe. A construção do fantástico na narrativa. Lisboa: Livros Horizonte, 1980 HANSEN, João Adolfo. O imortal e a verossimilhança. In: Teresa revista de Literatura Brasileira [6/7]. São Paulo, p.56-78, 2006.

MATANGRANO, Bruno Anselmi; TAVARES, Enéias. Fantástico brasileiro: o insólito literário do romantismo ao fantasismo. Curitiba: Arte \& Letra, 2018.

ROAS, David. A Ameaça do Fantástico: aproximações teóricas. Tradução de Julián Fuks. São Paulo: Editora Unesp, 2014.

SÁ, Márcio Cícero de. Da literatura fantástica (teorias e contos). 2003. 141 f. Dissertação (Mestrado em Teoria Literária e Literatura Comparada) - Universidade de São Paulo, São Paulo, 2003.

SILVA, Lucélia Magda Oliveira da. Figurações do fantástico: a influência de Poe em obras machadianas. In: ARAÚJO, Naiara Sales (org.). Literatura fantástica, ficção científica e literatura gótica: interfaces e diálogos entrelaçados. São Luís: EDUFMA, 2018.

TODOROV, Tzvetan. Introdução à literatura fantástica. Tradução de Maria Clara Correa Castello. 4ª ed. São Paulo: Perspectiva, 2017.

Recebido em 11/o1/2020. Aprovado em 04/06/2020. 